\title{
Improving the heating networks efficiency by implementing instrumental methods of control
}

\author{
$T O$ Politova $^{1, *}$, Sh $G$ Ziganshin $^{1}, E R$ Bazukova , $A V$ Busarov $^{2}$ \\ ${ }^{1}$ Kazan Power Engineering University, 420066, 51, Krasnoselskaya st., Kazan, Russia \\ ${ }^{2}$ Center for Industrial Safety Expertise, 420140, 90 A, Y. Fuchik st. Kazan, Russia
}

\begin{abstract}
Problems of increasing the reliability and efficiency of heating networks operation are closely related to the reduction of costs for the repair and restoration activities. The high cost of installation and emergency restoration work in the conditions of a shortage of funds dictates the need to develop and implement new methods of maintenance. Diagnostics of heat networks allows to determine their technical condition, to identify the most decrepit sections of pipelines for the purpose of repair work.
\end{abstract}

\section{Introduction}

In accordance with the Energy Strategy of Russia for the period up to 2035, the priority areas for the development of the country's economy energy sector are the creation of highly efficient energy systems and complexes and an increase the use efficiency of the energy resources in energy-intensive industries.

Due to the high deterioration of energy facilities, their modernization is one of the key issues for shifting the Russian economy to the path of innovative development. Energy saving issues are of particular importance and become priorities for all enterprises.

There is about a third ( $29 \%)$ of heating networks in a state of usage factor in Russia. To ensure reliable heat supply, $4-5 \%$ of pipelines need to be updated annually. There is lack of funds for it [1].

Chronic underfunding of the heating industry leads to social tensions. There are often breakthroughs of heating pipes occurring in winter. Tens of thousands of people remain without heating in the cold. For example, in early 2019 in Barnaul, heating and hot water supply to 224 residential buildings, 17 social facilities and 29 administrative buildings ceased. Earlier, even more large-scale accidents occurred in Samara and Tver, where trunk pipelines broke through. Work on the replacement of decrepit heating networks should be conducted annually. Only such an approach will allow the equipment to be maintained in working condition [1].

\section{Analysis of problem}

Based on the analysis of the heat supply industry state, it follows that increasing the reliability of the centralized heat supply systems is one of the urgent scientific and practical tasks of developing the country's energy sector.

The weakest link of the heat supply system is the heating network. Damage to heating networks, despite the increase in the volume of changes in recent years, remains at a high level.

Major accidents, as well as an increase the damageability of underground heat pipelines, lead to significant overspending of thermal energy and fuel, additional investments, and high human labor costs.

The studies conducted by the authors showed that the amount of damage to heating networks elements is on average from 20 to 40 pieces per $100 \mathrm{~km}$ of the route and increases with the increasing pipeline period of service. Table 1 presents the average data on the heating networks damageability of Kazan for 4 years.

Table 1. Average damageability of heating networks of Kazan.

\begin{tabular}{|c|c|}
\hline Pipelines & $\begin{array}{c}\text { Average damageability for 4 } \\
\text { years }\end{array}$ \\
\hline Trunk & 490 \\
\hline Quarter (heating) & 1581 \\
\hline Hot water supply & 967 \\
\hline
\end{tabular}

During the damage analysis, the main causes of the incidents were highlighted:

- defect of valves;

- hole;

- external corrosion.

Since the level of deterioration of heating networks in our country is very high, it exceeds $70 \%$, in some regions, while there is a lack of funding. For this reason, a complete reconstruction is often impossible. Therefore, the choice falls in favor of local repairs.

In order to carry out repair work, diagnostics of heating networks is carried out, which allows to determine their condition, select the most decrepit and potentially dangerous pipelines sections.

Diagnostics of pipelines is carried out in order to obtain data on:

Corresponding author: politovatatyana@ya.ru 
- locations, level and degree of danger, from the standpoint of leakage, corrosion damage to the metal of pipes - such defects as thinning of the pipe wall from internal and/or external corrosion by more than $30 \%$ of the nominal value;

- detection of the location of heat carrier flow (leakage);

- factors causing the intensification of corrosion processes at the site (stray currents, silting and flooding of channels, etc.).

Currently in Russia, the most common methods for diagnosing heating networks pipelines of underground installation are $[2,3]$ :

- testing of pipeline sections for density and strength in accordance with the technical operation rules by creating a pressure inside the pipe of at least 1.25 from the operating one;

- a method of soil excavation with the opening of the engineering network channel, which is widely used in the search for defects during operation or after conducting scheduled tests of heating networks. This method is governed by the instruction for heating networks [7] and is based on an external examination of building structures and the state of thermal insulation materials and the pipeline.

Monitoring of the heat pipelines metal state without opening the heating mains is carried out in isolated cases, on the main pipelines. The cost of such an examination for many companies is extremely high.

The task of searching a pipeline defect and determining the cause of its occurrence occupies a special place. And not only the time to limit the supply or transmission of heat, traffic and pedestrians depends on its solution, but also the costs associated with the volume of ground works and subsequent improvement to restore the damaged landscape of the area.

\section{Method of solving}

One of the ways to solve the improving the efficiency of heat supply is the transition to the creation of a monitoring and diagnostic system with the subsequent formation of a system for the major repairs of heating networks. The basis of this system is the automated control of the pipelines and technical equipment state.

Analysis of methods for determining the state of heating networks showed two main directions for solving the problem:

1. Carrying out the control of heat pipelines by instrumental methods.

2. Prediction of damage and assessment of the reliability of heating networks based on statistical methods.

Detection of leaks from pipelines is a difficult technical problem, the solution of which requires special equipment. The main control methods are: acoustic, correlation, thermal.

An integrated approach to solving the problem of detecting water leaks from a pipeline using instruments significantly increases the accuracy of detection of an emergency site. At the same time, the use of diagnostic methods determining the condition of the pipeline should help identify potentially dangerous hydrogeological areas. It would justify the need for additional waterproofing, drainage, insulation of channel overlaps, and the possibility of developing ways to efficiently ventilate them to dry insulation plating and prevent condensate from falling out.

However, in the conditions of market economy it is important to provide a feasibility study on the efficiency of the heating networks reconstruction, because the final result is investment in the construction of the facility and, as a consequence, operating costs. There is a need to determine not only the reliability of the system, but also the effectiveness of the system.

The basis for ensuring the reliability of heating networks is the knowing of the real state of their elements. It ensures efficient use of resources for ensuring operability. Until recently, repair and relaying of heating networks were often carried out according to the service life and depreciation rate. However, the condition of heating networks elements depends on the specific conditions of their operation, which can both accelerate and slow down their destruction, which leads to satisfactory reliability of elements with high depreciation usage.

\section{Results}

Nowadays, there are several basic approaches that allow in practice to assess the effectiveness of the implementation of diagnostic methods. Economic efficiency consists of direct and indirect saving. Direct saving can be attributed to reduced equipment repair costs, an increase the real turnaround time due to the exclusion of scheduled repairs. In addition, it also reduces the cost of repair by identifying defects, the elimination of which does not require dismantling. Indirect cost saving is due to lower costs that are not directly related to production costs (losses incurred as a result of unplanned downtime of equipment, release of defects, as well as the costs of eliminating accidents).

Table 2. Calculation of the cost of replacing 1 1.m. pipeline in traditional insulation.

\begin{tabular}{|c|c|c|c|c|c|}
\hline Diameter & Cost, rubles & Diameter & Cost, rubles & Diameter & Cost, rubles \\
\hline 57 & 7031 & 159 & 10219 & 530 & 25993 \\
\hline 76 & 7485.6 & 219 & 12946 & 630 & 33475 \\
\hline 89 & 7968.8 & 273 & 15865 & 720 & 37706 \\
\hline 108 & 9112.5 & 325 & 20292 & 820 & 48021 \\
\hline 133 & 10003 & 426 & 22517 & & \\
\hline
\end{tabular}


There is the cost of replacing $11 . \mathrm{m}$. pipeline in traditional insulation of different diameters in Table 2. During calculating the cost, the costs include restoration works (chernozem dumping, grass sowing, planting trees, restoring small architectural forms, etc.), cutting and adding soil during planning, as well as dismantling and paving works.

The damage volume depends on the time of the recovery period, that is, the time taken to detect and repair the damage, as well as to restore the heat supply. Usually this time is measured in hours and sometimes in dozens of hours.

As a rule, damage to heating networks leads to significant material damage, estimated at tens of thousands of rubles. The average cost of replacing 1 linear meter pipeline, depending on the heating networks damageability, is presented in Table 3.

Table 3. The average cost of replacing of 1 linear meter pipeline.

\begin{tabular}{|c|c|}
\hline Pipelines & $\begin{array}{c}\text { The average cost of replacing, } \\
\text { rubles }\end{array}$ \\
\hline Trunk & 16435765.99 \\
\hline Quarter (heating) & 20668144.05 \\
\hline Hot water supply & 7247785.392 \\
\hline
\end{tabular}

The total economic efficiency of using nondestructive testing methods in heating networks can be calculated using the following universal formula:

$$
E=\sum_{i=1}^{n}\left(Z_{i 1}-Z_{i 2}\right)
$$

where $\mathrm{i}$ - serial number of factor taken into account, $\mathrm{n}-$ the whole number of factors taken into account, $\mathrm{Zil}$ and $\mathrm{Zi} 2$ - cost of effect of i-factor before and after the implementation of diagnostic methods and tools, respectively.

The results of calculations for the control of heating networks are presented in Table 4.
Table 4. Costs for control.

\begin{tabular}{|c|c|}
\hline Pipelines & $\begin{array}{c}\text { The average cost for control, } \\
\text { rubles }\end{array}$ \\
\hline Trunk & 1666000 \\
\hline Quarter (heating) & 5375400 \\
\hline Hot water supply & 3287800 \\
\hline
\end{tabular}

The data on the cost of monitoring and eliminating accidents for trunk and quarter pipelines and hot water supply networks are presented on the histogram of fig. 1 .

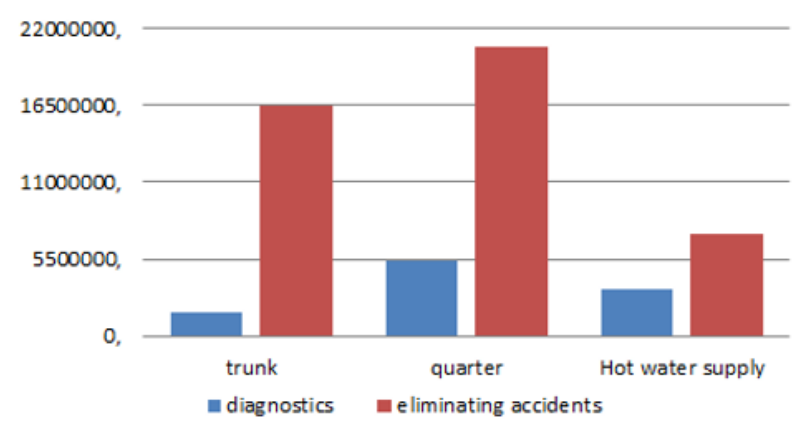

Fig. 1. Cost to control and accident elimination.

During determining the exact location of a defect or leak, it is possible to minimize the volume of groundwork. A timely monitoring allows you to send the funds scheduled for repairs to where the accident is more likely to occur.

\section{Conclusion}

Conducting engineering diagnostics in the winter period allows you to more efficiently prepare for the repair and restoration works in the summer period.

The ranking of the areas to be relayed according to the results of the control allows reducing the number of leaks during reducing the volume of relays. Information on the intervals ranked as areas of the worst condition and preventive maintenance of works on them also contributes to reducing the number of leaks. High accuracy of detection of damage to pipelines significantly reduces the time spent on detecting bursts of heating networks, reduces the cost of eliminating

Table 5. The results of the heating networks pipelines inspection in pitting locations.

\begin{tabular}{|l|c|c|c|c|c|c|c|c|c|}
\hline Pit locations & \multicolumn{3}{|c|}{ Held pitting } & \multicolumn{3}{c|}{$\begin{array}{c}\text { Recognized fit heating } \\
\text { networks pipelines }\end{array}$} & \multicolumn{3}{c|}{$\begin{array}{c}\text { Rejected heating networks } \\
\text { pipelines }\end{array}$} \\
\hline & Amount & $\%$ & $\begin{array}{c}\text { Costs, } \\
\text { rubles }\end{array}$ & Amount & $\%$ & $\begin{array}{c}\text { Costs, } \\
\text { rubles }\end{array}$ & Amount & $\%$ & $\begin{array}{c}\text { Costs, } \\
\text { rubles }\end{array}$ \\
\hline On asphalt & 23 & 20.5 & 158217 & 6 & 23.1 & 41274 & 17 & 73.9 & 116943 \\
\hline $\begin{array}{l}\text { On asphalt- } \\
\text { lawn }\end{array}$ & 5 & 4.5 & 34395 & 1 & 20 & 6279 & 4 & 80 & 27516 \\
\hline On lawns & 84 & 75 & 177927 & 52 & 61.9 & 111384 & 32 & 38.1 & 68544 \\
\hline Total & 112 & 100 & 372540 & 59 & 53.7 & 159537 & 53 & 47.3 & 213003 \\
\hline
\end{tabular}


them. Each leak accurately detected through instrumental control avoids an average of 2 pits.

The economic efficiency of instrumental control of pipelines can be seen on the example of carrying out planned pits, the results of which are presented in Table 5.

\section{References}

1. S. Volokhina, Pipes will burn: The Ministry of Construction stated the need to repair $30 \%$ of the heating networks, Economics and Management (2019)

2. A.V. Vakatov, A.Ye. Buklov, Experience of engineering diagnostics of heating networks in Togliatti, Heat Supply News, 9(73) (2006)

3. M. Yu. Zvyagintsev, The experience of diagnostics of heating networks pipelines by the method of acoustic tomography in combination with a contactless magnetometric method, Heat Supply News, 03(139) (2012)

4. V.Ye. Voyevodov, Experience of the service of diagnostics and control of heating networks in Syktyvkar. Part 1, Heat Supply News, 04(116) (2010)

5. A.A. Alexandrov, S.Ye. Babushkin, A.R. Tamvilius, On the operational efficiency of the remote control of PPU heat pipelines, Heat Supply News, 2(218) (2019)

6. L.V. Chupin, V.I. Shlapakov, Analysis of the accident rate of heating networks and the planning of pipe replacement in an automated control system for the heating networks operation, Heat Supply News, 11 (2014)

7. V.I. Matveyev, Experience in the diagnosis of heating networks at the Municipal Unitary Enterprise Yoshkar-Ola TPP-1, Heat Supply News, 7(11), 24 - 27 (2001)

8. G.A. Bigus, A.B. Schastlivtsev, M.A. Sabrekov, Acoustic emission control on pipelines of the main heating networks of the Norilsk industrial region, Heat Supply News, 11(195) (2016)

9. I.V. Grankin, D.B. Domracheyev, Experience of using the method of acoustic diagnostics of heating networks pipelines, Heat Supply New, 2, 42-48 (2008)

10. Sh.G. Ziganshin, Yu.V. Vankov, E.V. Izmaylova, Monitoring the technical condition of pipelines by acoustic methods, 160 (2015)

11. T.G. Gorbunova, Yu.V. Vankov, T.O. Politova, Calculation and evaluation of the reliability index in the designing heating networks [Electronic resource], Engineering Bulletin of Don, 1 (2014) http://ivdon.ru/magazine/archive/n1y2014/2228 Russian language

12. A.M. Geroyeva, I.Yu. Zilberova, Forecasting and diagnostics of the technical condition of the municipal infrastructure facilities [Electronic resource], Engineering Bulletin of Don, 4 (2012) http://www.ivdon.ru/magazine/archive/n4p1y2012/
1074 (free access) - Title from the screen. - Russian language

13. Yu.A. Vankov, T.G. Gorbunova, T.O. Politova, Sh.G. Ziganshin, Functional reliability of heating networks in Kazan: Theory and Practice, RELIABILITY AND QUALITY (2012)

14. Yu.A. Vankov, T.G. Gorbunova, T.O. Politova, Sh.G. Ziganshin, D.N. Zagidullin, Practical application of reliability index in designing heating networks [Electronic resource], Prescopus Russia: Open journal (2013)

15. A.V. Filimonov, Leak detectors for the searching leaks on the heating networks, Heat Supply News, 5 (2009) 